\title{
Deployment of Infrared Inspection Technologies at Sandia National Laboratories
}

Experimental Mechanics/NDE \& Model Validation Non Destructive Test Laboratory Sandia National Laboratories Albuquerque, New Mexico United States of America David G. Moore (505 ) 844-7095 Enrico Quintana (505) 844-5718 Kyle R. Thompson (505) 844-0347 
- About Sandia National Laboratories

- Infrared Basics

- IR Capabilities at Sandia National Laboratories

- Thermal Wave Inspection Set-up and Applications

- Infrared Capabilities and Limitations

- Conclusions 


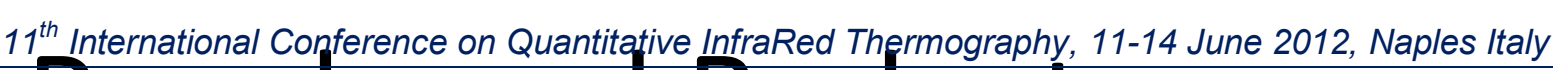 People and Budget 300}

(As of October 11, 2011)

-On-site workforce: 11,876

-Regular employees: 9,122

FY11 Operating Revenue

-Gross payroll: $\$ 943$ million

\section{Technical staff $(4,557)$ by discipline}
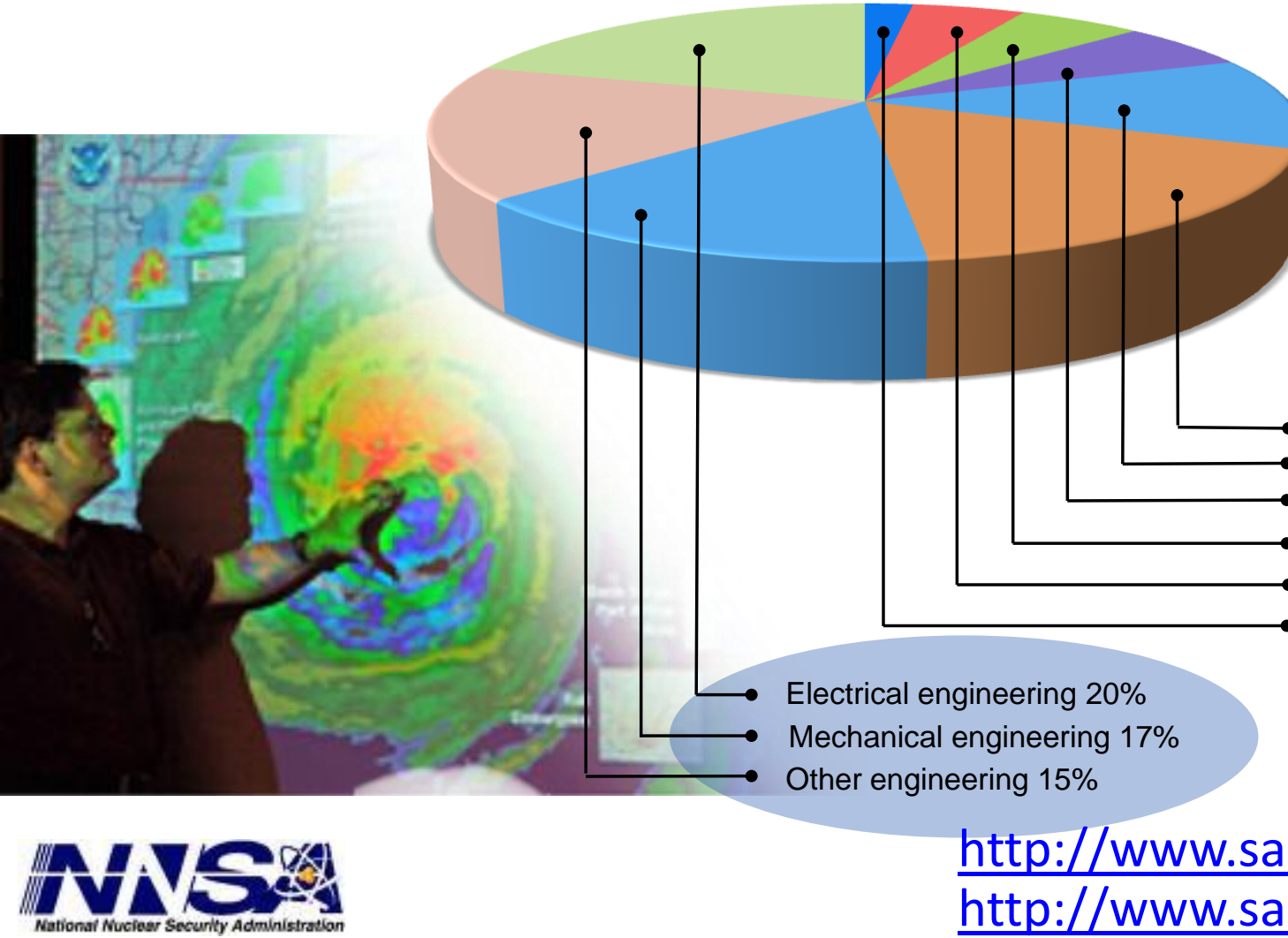

(Operating Budget)

$\square$ Nuclear Weapons

$\square$ Defense Systems \& Assessments

$\square$ Energy, Climate \& Infrastructure Security

$\square$ International, Homeland, and Nuclear Security

Computing $17 \%$

Other fields $12 \%$

Other science 6\%

Physics 6\%

Chemistry $5 \%$

Math 2\%

\section{\$2.4 billion}

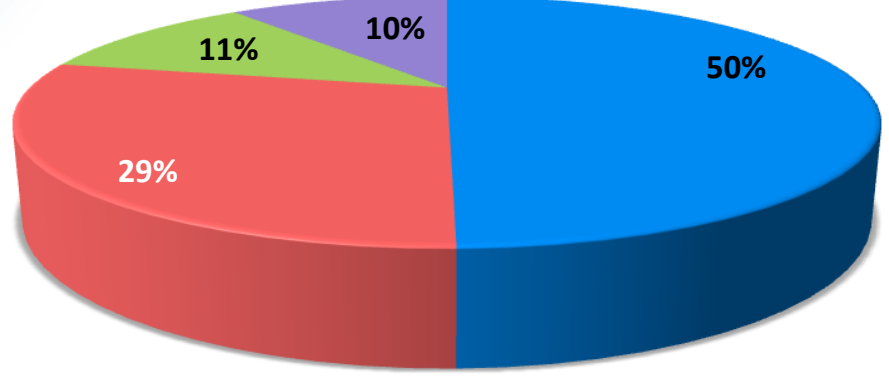

http://www.sandia.gov/about/faq/ http://www.sandia.gov/about/locations/

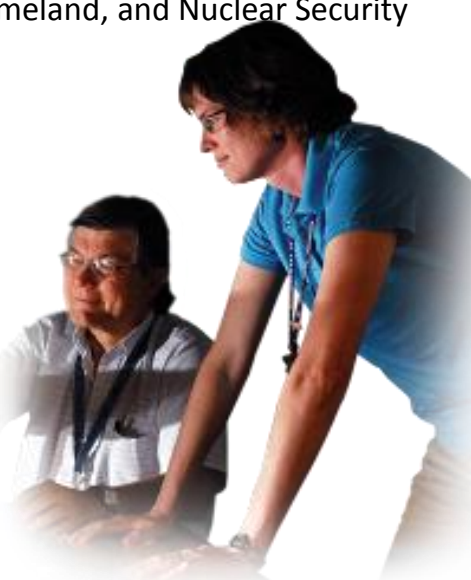




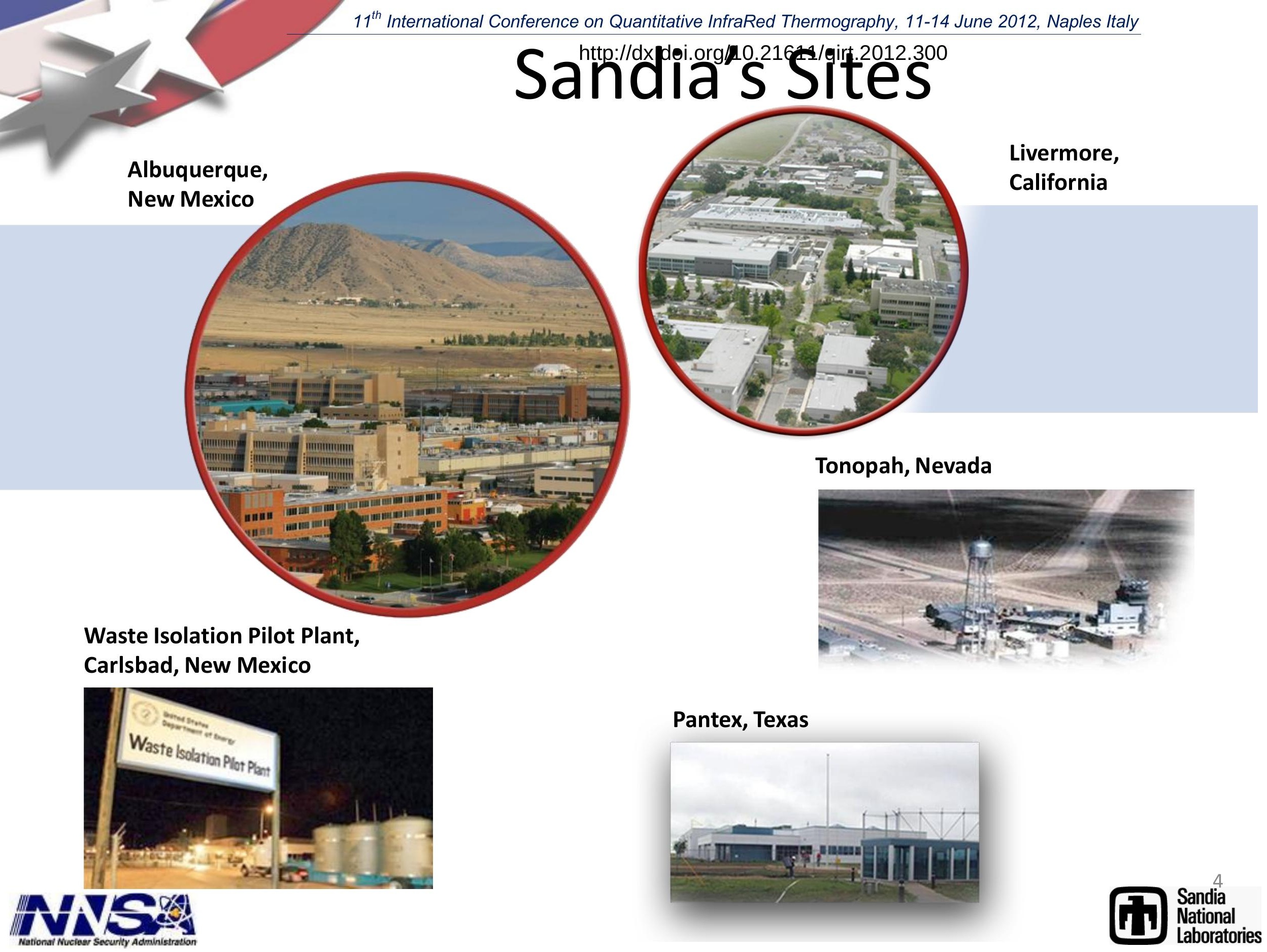




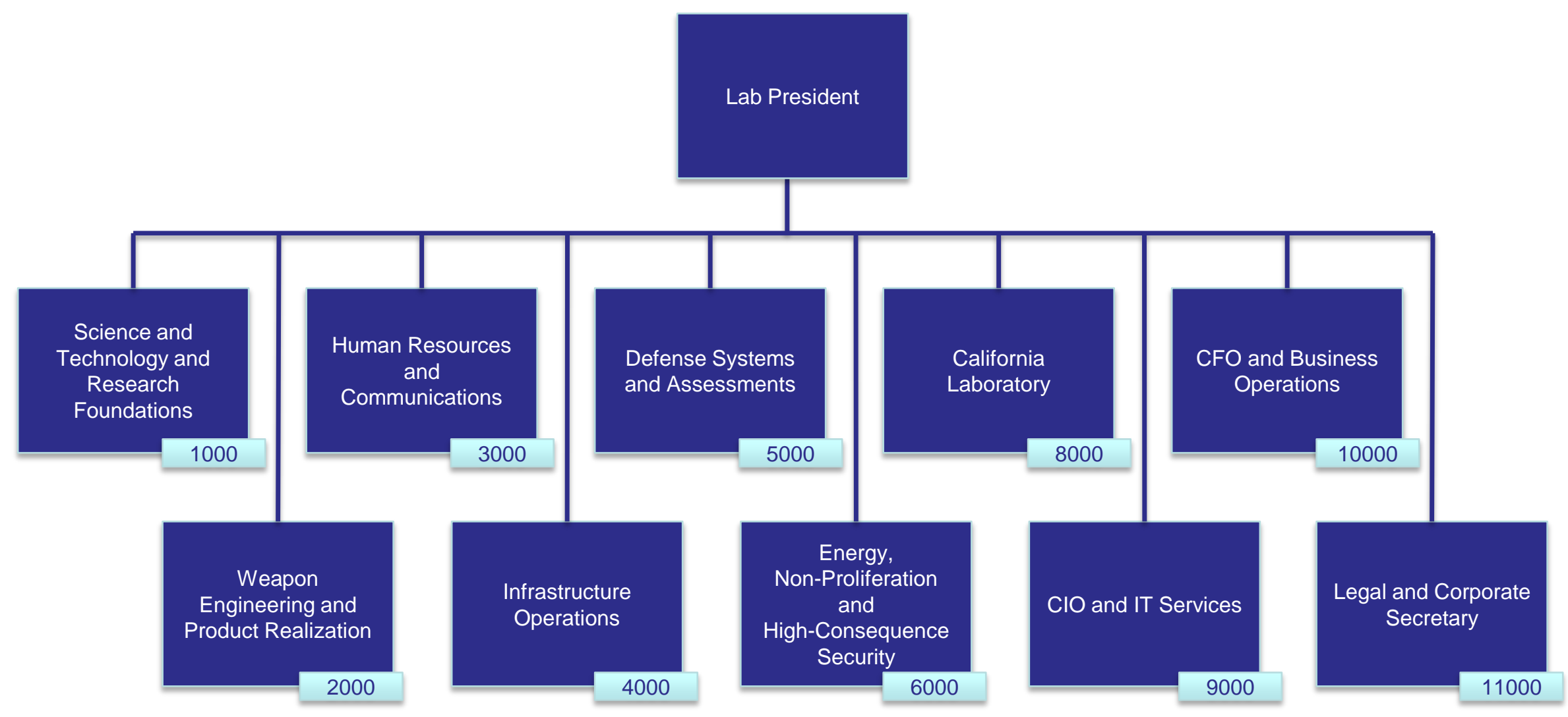

- Division 1000 : Science and Technology and Research Foundations

- Center 1500 : Engineering Sciences

- 1520 : Solid Mechanics and Structural Dynamics

- Organization 1522 : Experimental Mechanics, NDE, and Model Validation 


\section{Non-Destructive Evaluation (NDE)}

- NDE at Sandia Includes a suite of technologies

- Radiography

- Computed Tomography

- Ultrasonic Diagnostics

- Eddy Current Testing

- Infrared Imaging

- Applications

- Research and Development

- Quality Control, Failure Analysis, \& Testing Diagnostics 


\section{Infrared Bi Basics}

- Active Thermography (AT) is defined as a technique where a stimulus is applied to a target to cause the target to heat or cool in such a way as to allow characteristics of the target to be observed by infrared imaging.

- The difference between active from passive thermography is the intentional application of heating, cooling or other excitation method that results in a temperature rise or fall in a target, as compared to an otherwise in situ (passive) target.

- In active thermography, the thermal response of a target to a heating (or cooling) event is analyzed to determine the subsurface structure or material properties of the target. The time at which temperature changes take place is often more important than the amplitude of the temperature change. 


\section{EchoTherm Equipment}

- EchoTherm Software processes thermographic signal reconstruction (TRS) and temperaturetime profiles.

- Mosaiq software converts live images into data files single

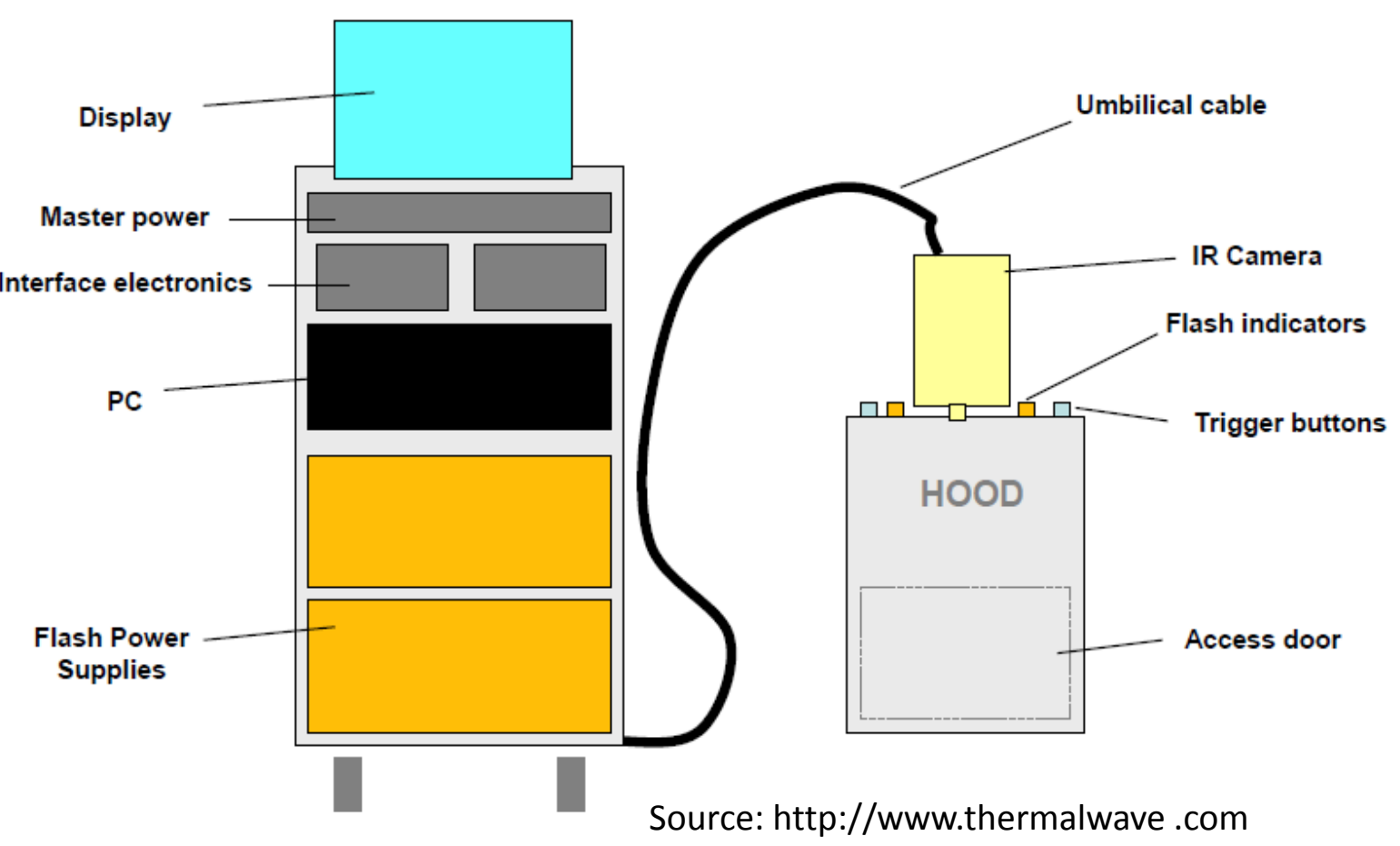
or multiple images.

The hood contains two xenon flash lamps, parabolic reflectors and uses 5000 Joules per lamp. FLIR 6106 camera (120 Hz @ 640 X 512 or 420 Hz @ 320 X $256 \mathrm{InSb}$ ) detector with 14 bit output. 

http://dx.doi.org/10.21611/qirt.2012.300

\section{VoyageIR Equipment}

- EchoTherm (TSR) and MOSAIQ software on a Toughbook laptop (Intel 2.26 $\mathrm{GHz}$ processor).

- The IR camera is a Microbolometer - $30 \mathrm{~Hz} @$ $320 \times 25614$ bit USB.

- Heat gun with trigger control.

- Handheld color touchscreen

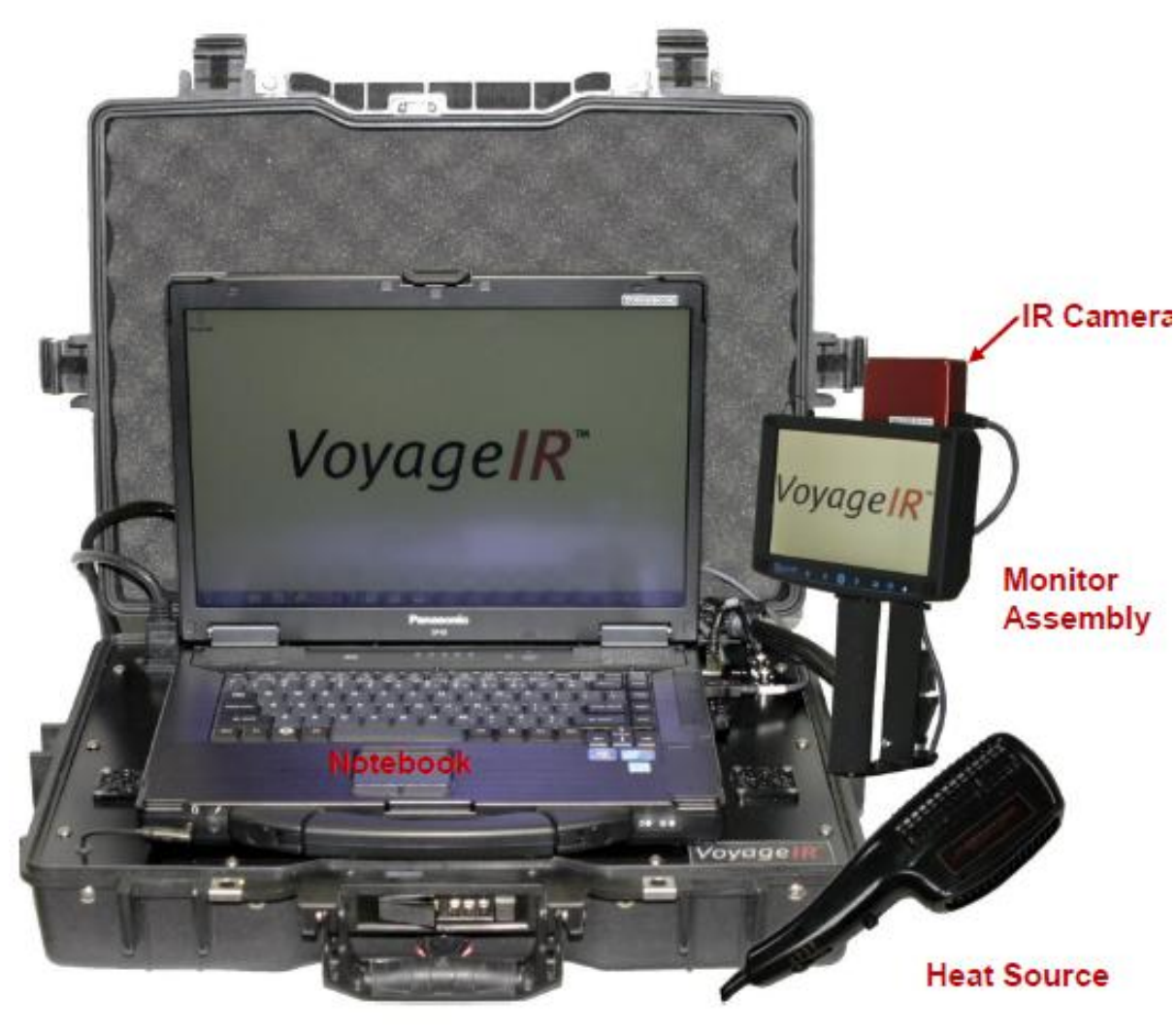
(live or saved images available). 
$11^{\text {th }}$ International Conference on Quantitative InfraRed Thermography, 11-14 June 2012, Naples Italy http://dx.doi.org/10.21611/qirt.2012.300

\section{Equipment Set-up}

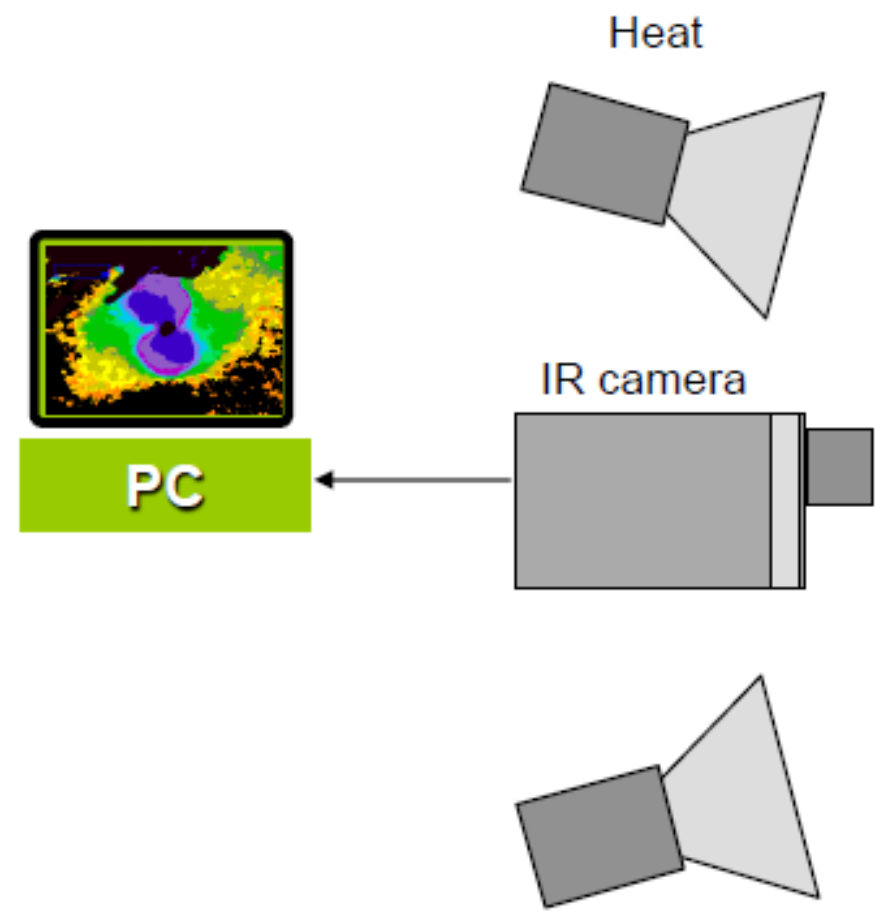

IR radiation

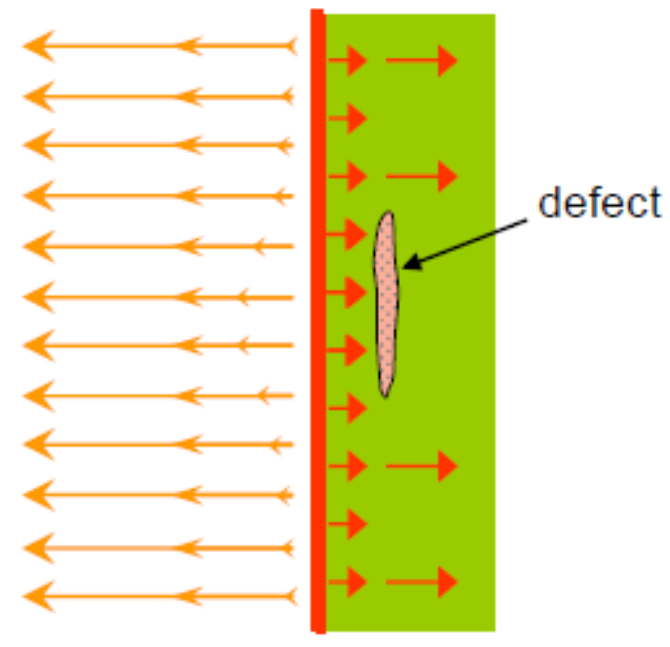

Heat conduction

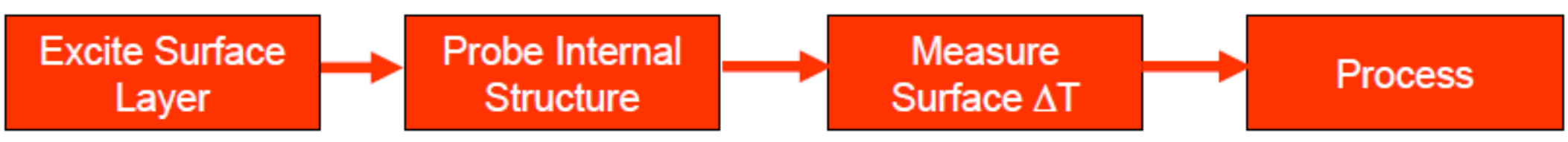




\section{Inspection Set-up and Applications}

Most composite parts are very complex. One current project is determining if IR inspection can detect for water ingress into composite honeycomb structures.

Below is an IR image with embedded water.

Both passive and active thermography Can detect the water.

Visually the honeycomb structure can be seen. The dark pixels are cool spots where water is within the cell structure. 


\section{Intensity Time Plot}

Cooling intensity is collected as a function of time. The event is analyzed to determine if there are changes in subsurface structure. Material thermal properties of the sample are used in baseline thermal measurements.

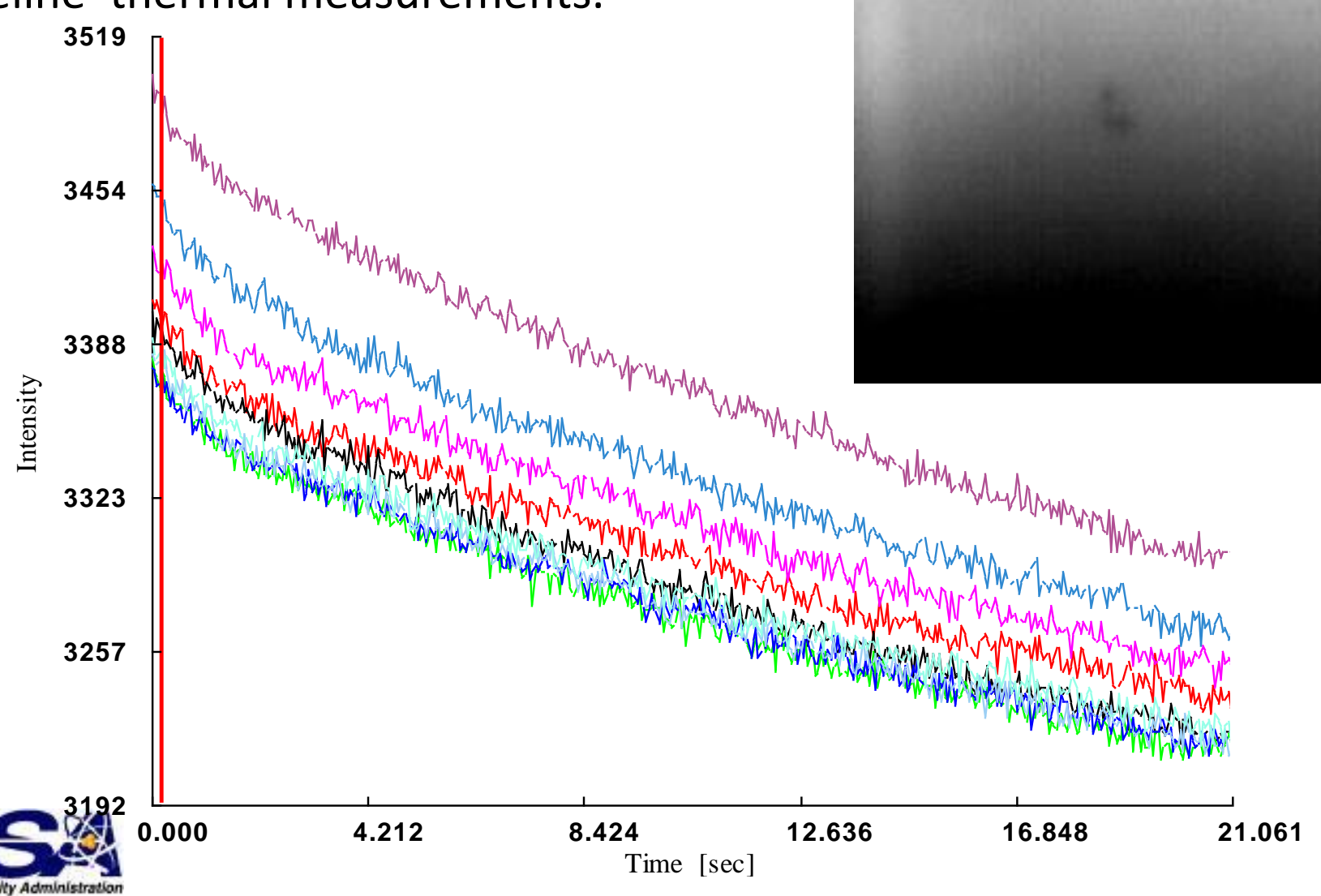

Each point above create a Intensity value per time step and the plotted. 


\section{Intensity Time Plot With Defects}

\section{Saturation}

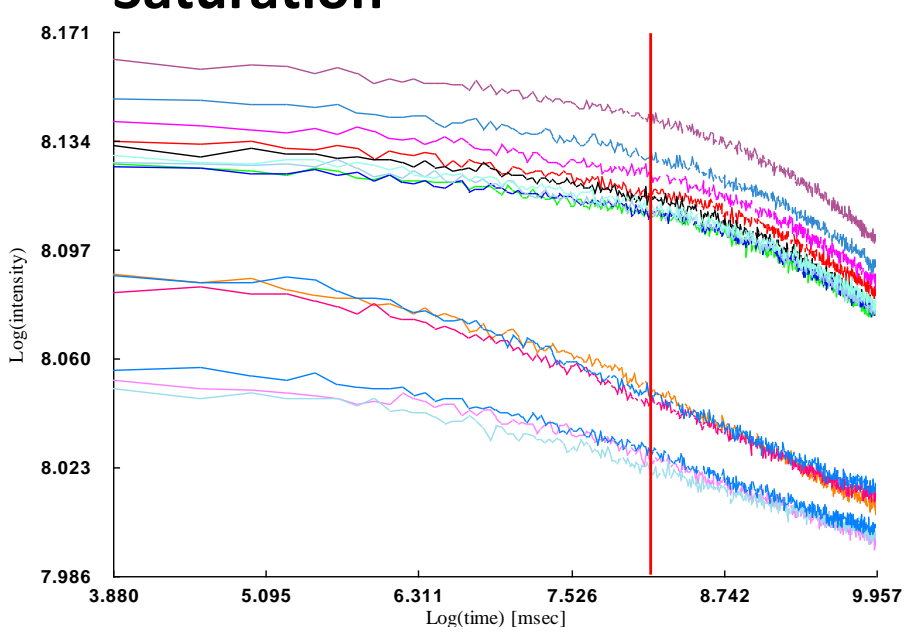

If high heat input levels are in the early frames the limits can be beyond the IR camera dynamic range. Saturation occurs. Trapped water is still absorbed by the incident heat.

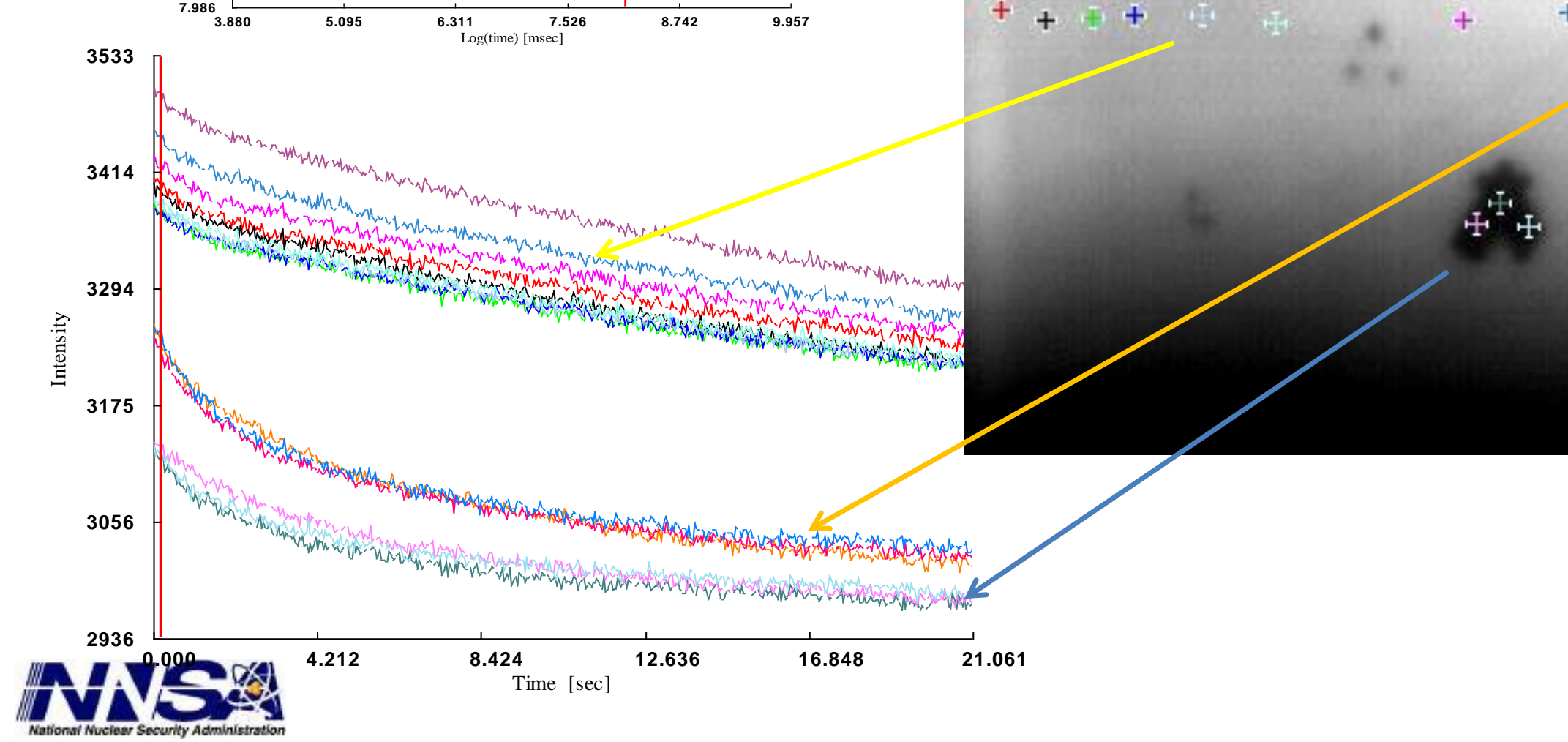



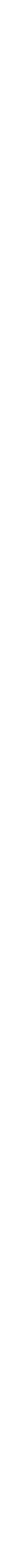


\section{Thick Composites with Pull Tab}

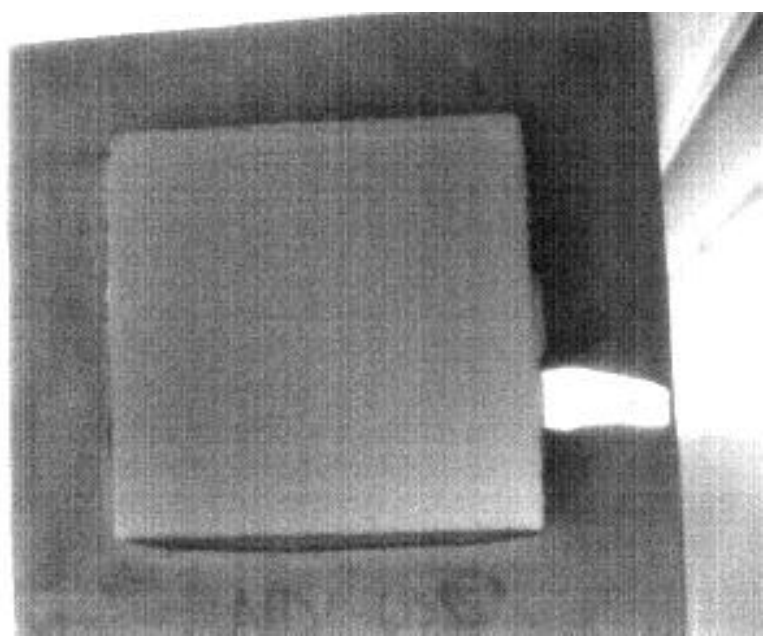

Pull tab

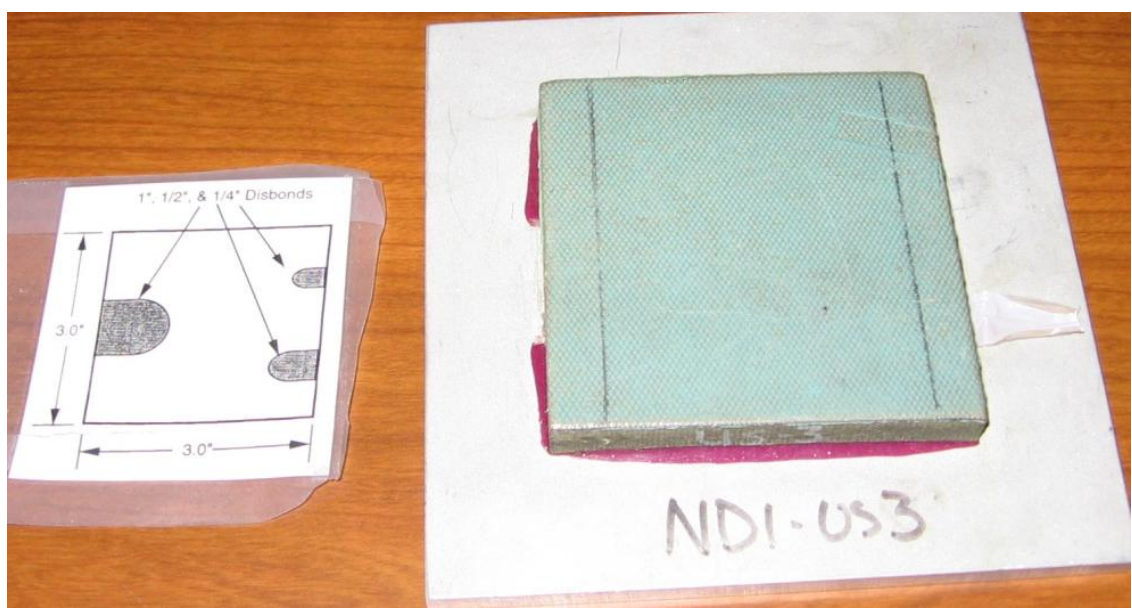

Thick composite bonded onto aluminum plate. Defects can not be detected using IR techniques. 


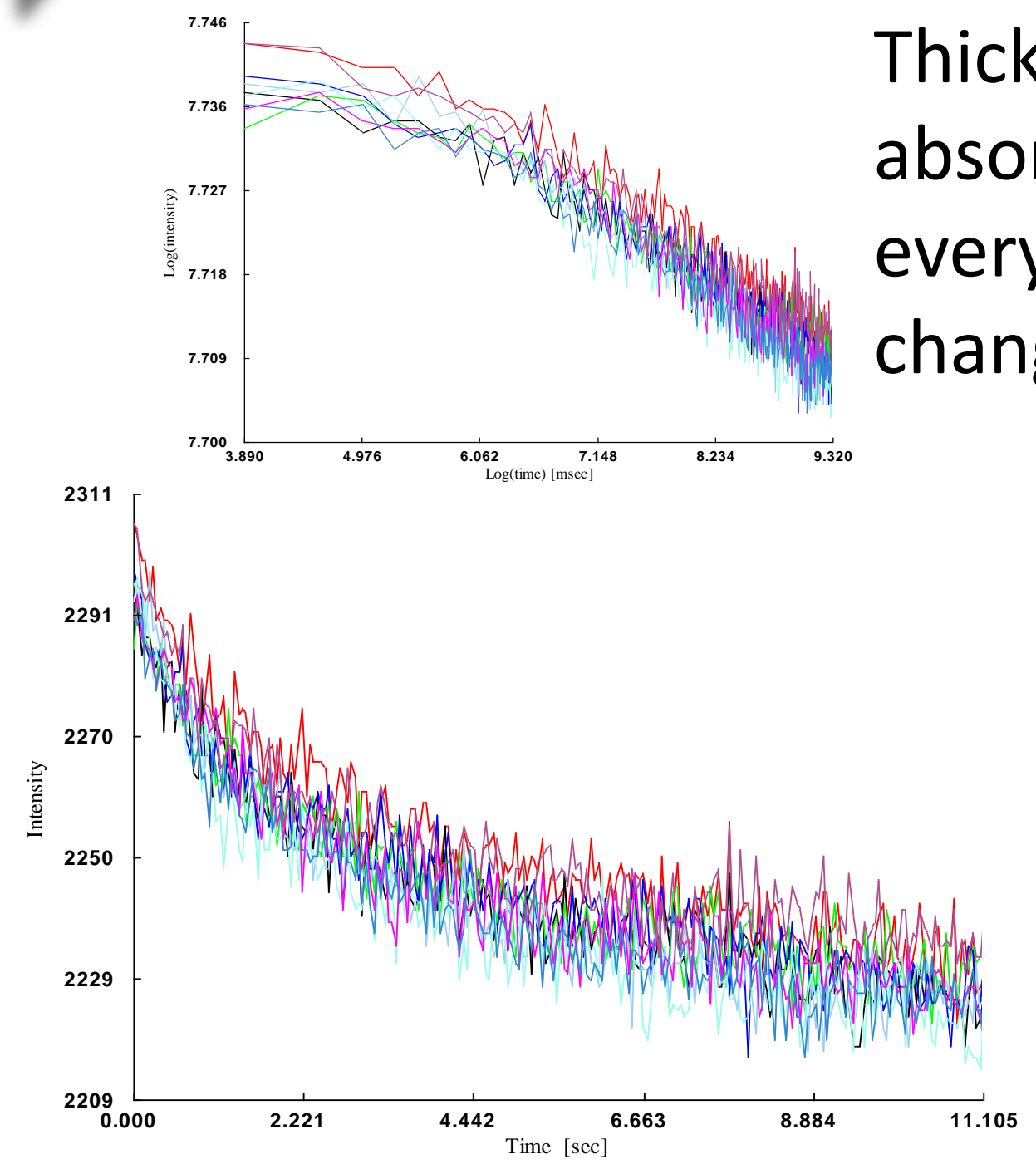

Thick composites create thermal absorption and scattering with every ply change. Thermal change occurs very slowly.

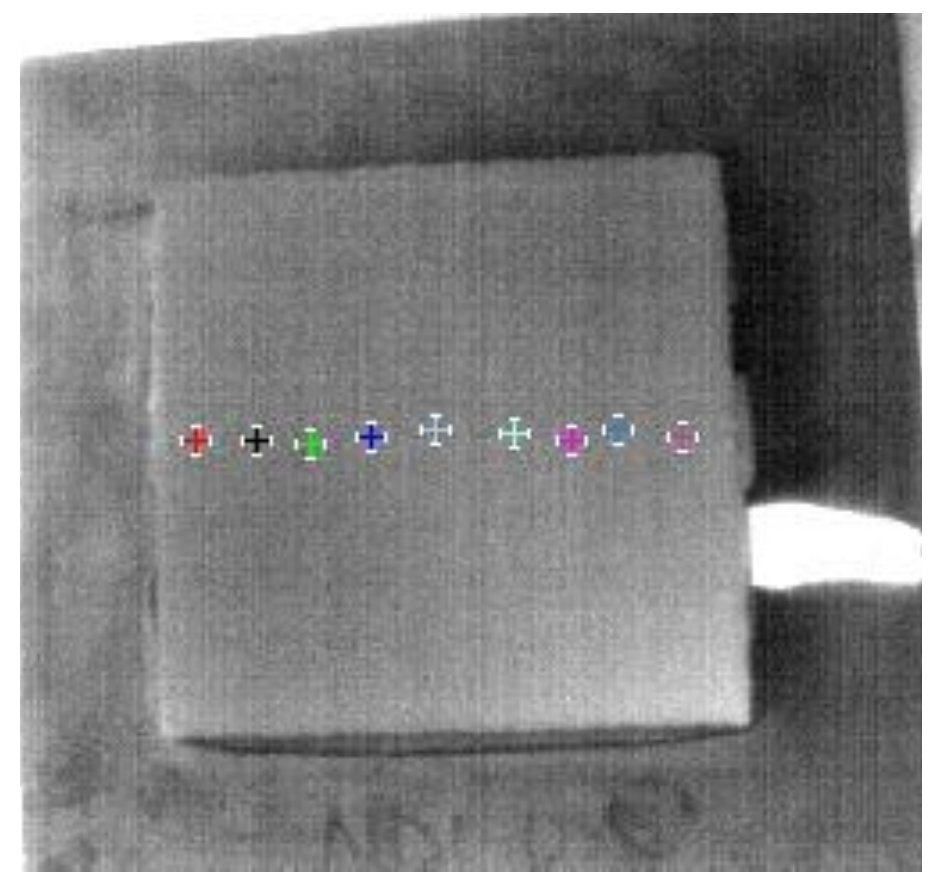




\section{Thick Fiberglass Sample}
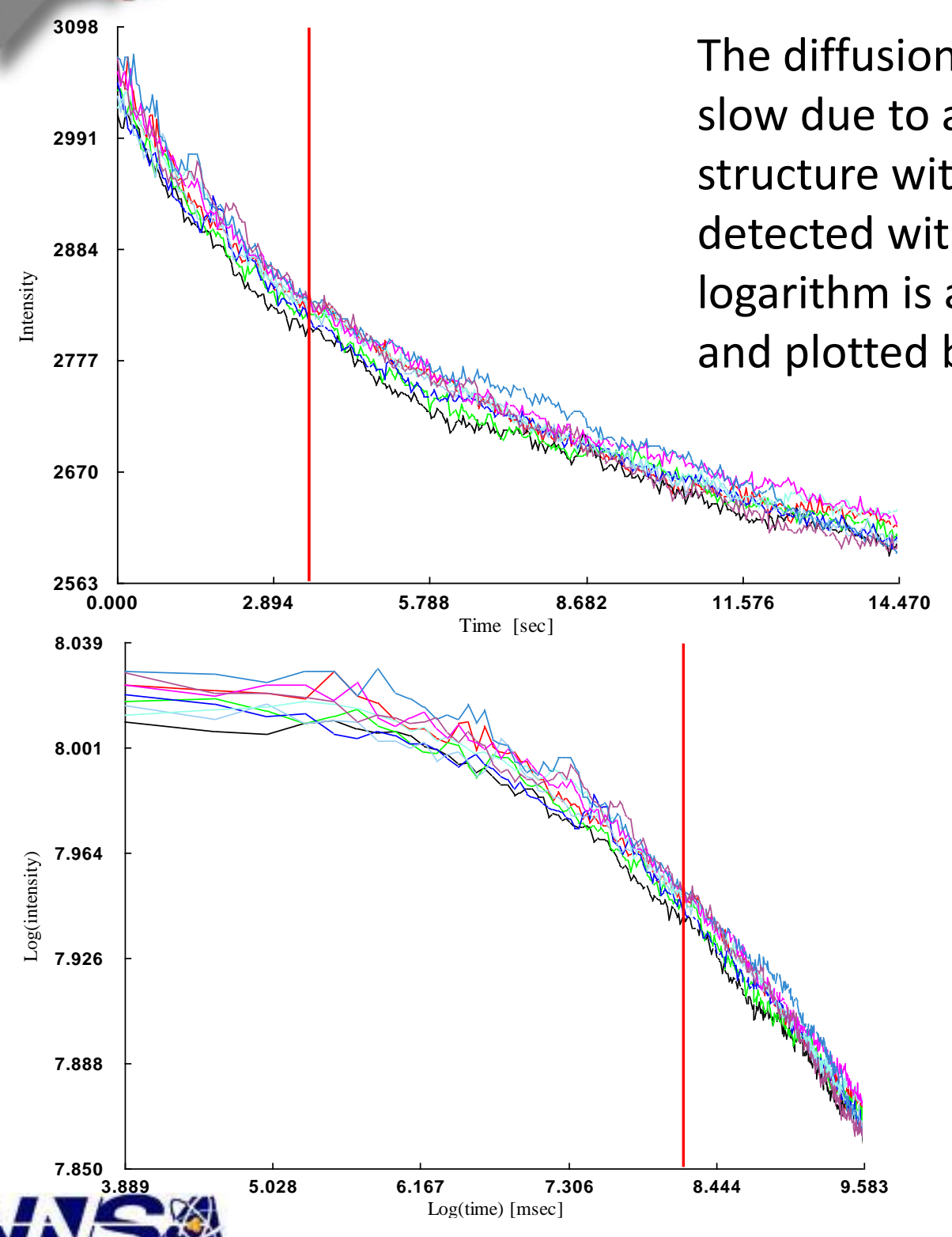


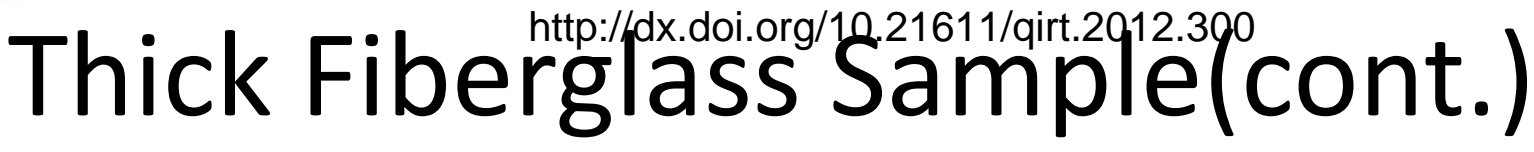
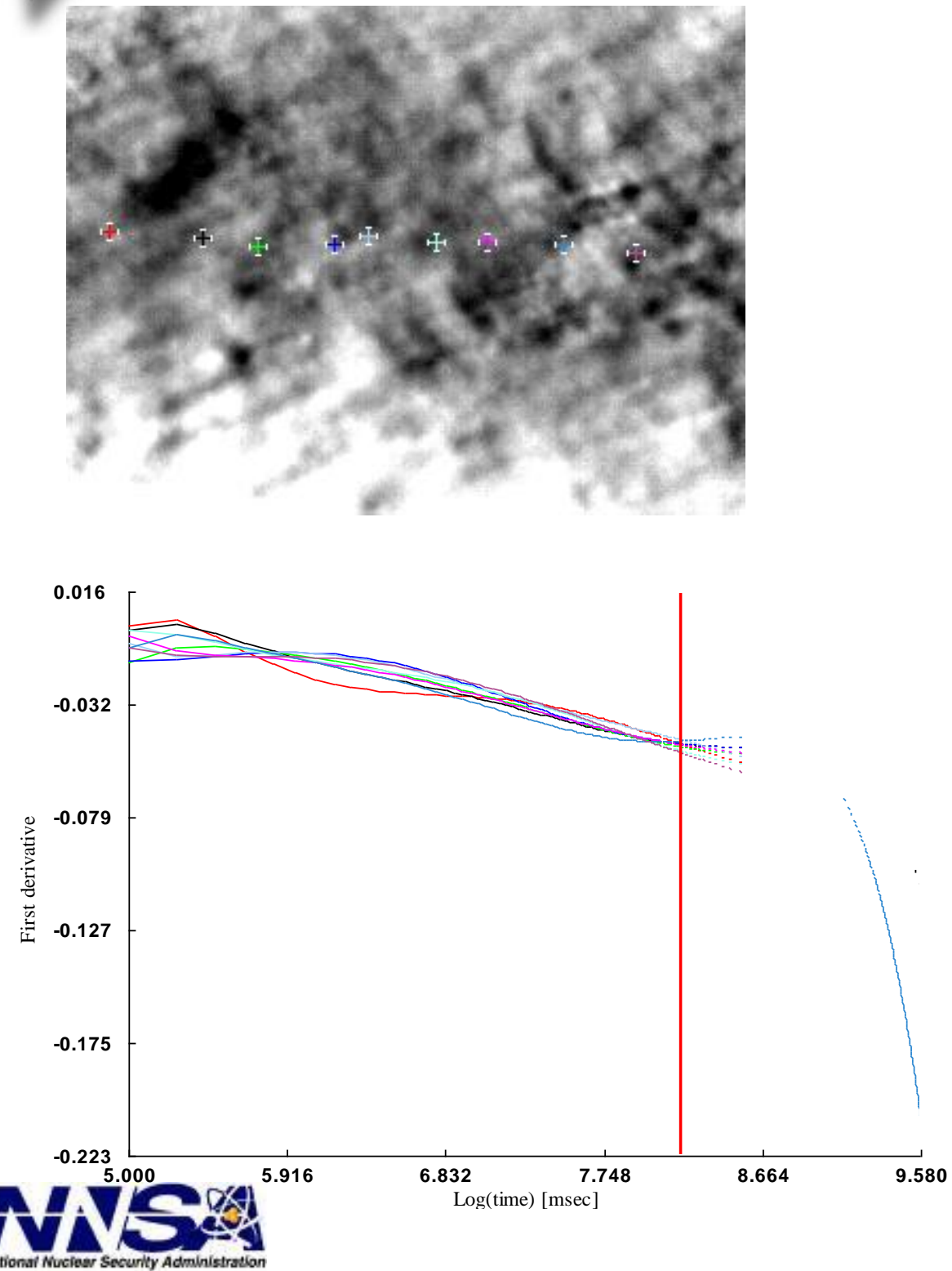

Thermographic Signal

Reconstruction fits the raw log-log data with a smooth function and uses the replica for additional processing. Once the coefficients are in the Log domain, a transform can be created to produce a first or second derivative. Below is the first derivative of each chosen pixel. 


\section{Thermal Impact Studies}

An engineering study is underway to address tool impact on composite layups. Loads of $10 \mathrm{~J}$ through $80 \mathrm{~J}$ were applied to composite samples. A thermal load was applied to each sample. The thermal decay of the composite was collected. Baseline, $10 \mathrm{~J}$ and $80 \mathrm{~J}$ impact samples are shown.

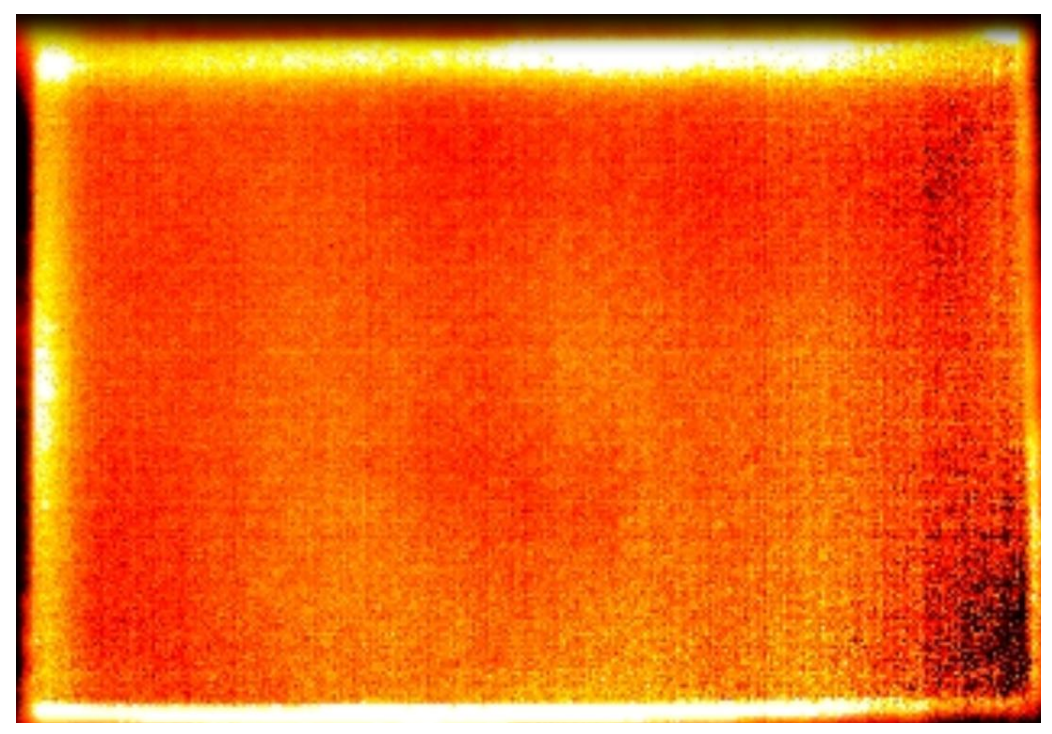

baseline

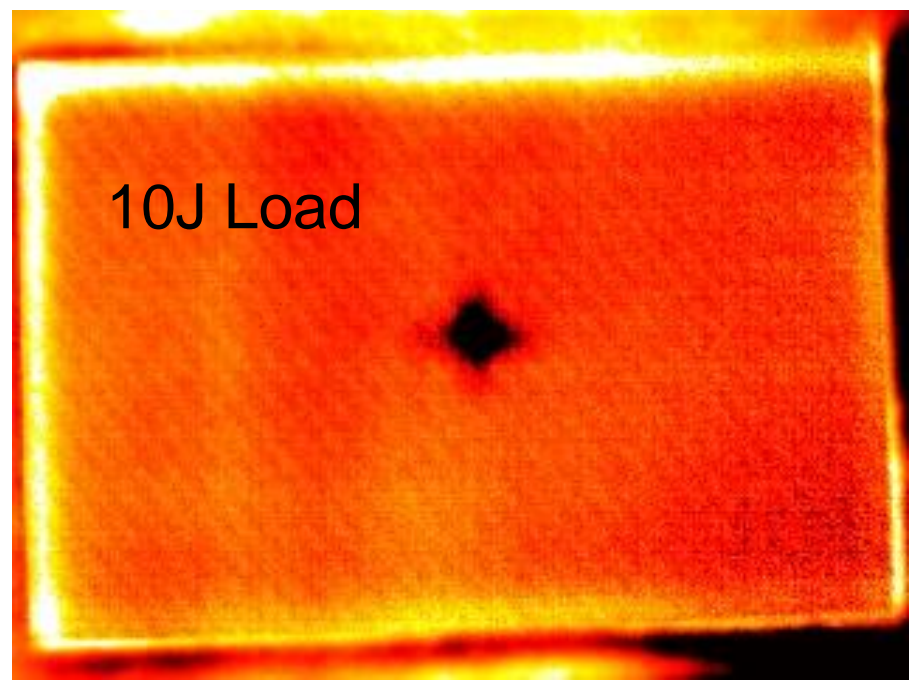

80J Load 


\section{Infrared Capabilities and Limitations}

- If the surface is shiny then light will be reflected from it. This may not allow enough heat to be deposited into the sample (low signal). A coating of low reflective paint (black) is required.

- Painted surfaces can be deceptive. The surface may be shiny however, the IR emissivity and optical absorption may be enough to produce data. A test with/without paint may be required. In many cases the derivatives remove reflection artifacts that appear in the raw image.

- Most composites appear shiny but can be imaged without painting. The slope processing features extract most required data.

- Many samples generate a reflection of the detector in the image. This effect can be removed in the TSR process or by subtraction of pre-flash images.

- If the log plot of a defect free point is extremely distorted then reflected radiation is the predominate signal and not conductive cooling. 


\section{Conclusions}

- Infrared technology will enhance Sandia's Nondestructive Inspection Laboratory diagnostic capabilities for future production needs.

- As new products mature IR inspection will be implemented (as required) to assist engineers. 